\title{
Conhecimento dos Professores que Atuam no Âmbito Escolar Acerca dos Primeiros Socorros
}

\author{
Knowledge of First-Aid Teachers at School
}

\author{
Rosa Caroline Mata Verçosa $a^{a}$; Mauricélia Michiles dos Santosa; Jefferson Ricardo da Silva ${ }^{\mathrm{a}}$; Marinnara Danielly Batista \\ Porfirio Silva ${ }^{\mathrm{b}}$; Raíssa Fernanda Evangelista Pires dos Santos*b
}

${ }^{a}$ Faculdade Estácio de Alagoas. AL, Brasil.

${ }^{b}$ Universidade Estadual de Ciências da Saúde de Alagoas. AL, Brasil.

*E-mail: raissa_lp7@hotmail.com

\begin{abstract}
Resumo
Acidentes na infância são comuns de acontecer no ambiente escolar havendo a necessidade de conhecimentos prévios sobre primeiros socorros pelos professores da educação básica. A falta de conhecimento técnico-científico adequado pode levar a condutas inapropriadas no atendimento de crianças vítimas de acidentes, acarretando em sequelas e podendo evoluir para a morte. Esse estudo tem como objetivo identificar os conhecimentos sobre primeiros socorros de professores que atuam no ambiente escolar frente a situações de urgência e emergência. Trata-se de uma revisão integrativa da literatura. A pesquisa foi realizada no período de novembro de 2019, nas bases de dados: Literatura LatinoAmericana e do Caribe Ciências da Saúde, Banco de Dados em Enfermagem e Medical Literature Analysis and Retrievel System Online, por meio da Biblioteca Virtual de Saúde., utilizando-se os descritores em ciências da saúde: "Knowledge", "School teachers" e "First aid". Foram incluídos oito estudos, publicados no período de 2014-2019. Os educadores apresentam conhecimento inadequado sobre primeiros socorros diminuindo a chance dos alunos receberem assistência adequada em caso de acidente na escola. Faz-se importante o treinamento dos professores escolares quanto às práticas de primeiros socorros, assim como, o reconhecimento de ações voltadas para prevenção e promoção dos agravos na saúde do escolar, objetivando melhor qualidade de vida das crianças.
\end{abstract}

Palavras-chave: Primeiros Socorros. Saúde Escolar. Conhecimento. Professores Escolares.

\begin{abstract}
Accidents in childhood are common to happen in the school environment with the need for prior knowledge about first aid by teachers of basic education. The lack of adequate technical-scientific knowledge can lead to inappropriate conduct in the care of children who are victims of accidents, resulting in sequelae and can evolve to death. This study aims to identify the knowledge about first aid by teachers who work in the school environment in the face of urgent and emergency situations. It is an integrative literature review. The research was carried out in the period of November 2019, in the databases: Latin American and Caribbean Literature Health Sciences, Nursing Database and Medical Literature Analysis and Retrievel System Online, through the Virtual Health Library., using the health science descriptors: "Knowledge", "School teachers" and "First aid". Eight studies, published in the period 2014-2019, were included. Educators have inadequate knowledge of first aid, decreasing the chance of students receiving adequate assistance in the event of an accident at school. It is important to train school teachers in first aid practices, as well as to recognize actions aimed at preventing and promoting health problems in schoolchildren, aiming at a better quality of life for children.
\end{abstract}

Keywords: First Aid. School Health. Knowledge. School Teachers.

\section{Introdução}

No Brasil, os acidentes são a maior causa de mortalidade entre crianças de 1 a 14 anos, e no âmbito escolar, estes acontecimentos vêm assumindo uma preocupação constante, visto que têm sido apresentados na literatura, com maior frequência em creches e pré-escolas, entre a faixa etária de 0 a 6 anos de idade (CABRAL; OLIVEIRA ,2017; CONTI; ZANATTA, 2014; LEITE et al., 2013).

Segundo Cabral e Oliveira (2017), acidentes na infância são comuns de acontecer no ambiente escolar, havendo a necessidade de conhecimentos prévios sobre primeiros socorros (PS) pelos professores da educação básica. A falta de conhecimento técnico-científico adequado pode levar a condutas inapropriadas no atendimento de crianças vítimas de acidentes, acarretando inclusive sequelas podendo evoluir para a morte.

Conceitua-se PS como prestação de cuidados imediatos dedicados às vítimas de acidente ou mal súbito independentemente da idade, fora do ambiente hospitalar, executadas por qualquer pessoa, treinada ou leiga, com o intuito de manter as funções vitais, proporcionar bem-estar e evitar agravamento do estado de saúde até a chegada da assistência especializada (MEIRELES, 2014).

No ambiente escolar, os acidentes constituem preocupação constante, sendo fundamental que os professores saibam como agir frente a esses eventos, como evitá-los e como realizar os PS, dessa forma, procurando evitar as complicações decorrentes de procedimentos inadequados, o que pode 
garantir a melhor evolução e prognóstico (LEITE, 2013).

Tendo como principais agravos à saúde infantil presenciado pelos educadores no ambiente escolar: convulsões, cortes profundos, fraturas de membros superiores e inferiores expostas ou não, entorses, cortes extensos com muito sangramento, quedas e engasgamentos. E alguns desses agravos, se não socorridos de maneira imediata e eficaz, apresentam risco de morte devido ao seu impacto na segurança e manutenção da vida desses estudantes (CARMO, 2017).

Os professores que atuam no âmbito escolar devem receber treinamentos formais e continuados para enfrentar as situações de emergências na escola, visto que as crianças e adolescentes em idade escolar são mais vulneráveis a sofrerem as situações de emergências devido a características próprias do desenvolvimento, físicas e comportamentais, incluindo vias aéreas mais estreitas, menor massa corporal e pele mais fina e mais suscetível a lesões (SLABE et al., 2016; SÖNMEZ et al., 2014).

Entretanto, é importante enfatizar que um atendimento de emergência inadequado pode comprometer ainda mais a saúde da vítima. Para que se possa prestar um socorro de emergência correto e eficiente, faz-se necessário que se dominem as técnicas de PS. Com o objetivo de evitar maiores complicações à saúde dos seus alunos e cumprir o compromisso com os pais, é imprescindível que os educadores estejam capacitados a agir diante de situações que exijam cuidados imediatos (LEITE, 2013).

De acordo com a Lei ${ }^{\circ} 13.722$ de 04 de outubro de 2018, que passou a vigorar em março de 2019, também conhecida como Lei Lucas, torna-se obrigatório a capacitação em noções básicas de primeiros socorros de professores e funcionários de estabelecimentos de ensino públicos e privados de educação básica e de estabelecimentos de recreação infantil; assim como a reciclagem desse treinamento para esses profissionais, tendo em vista diminuir os risco mediante a uma ocorrência de incidente até à chegada de ajuda profissional (BRASIL, 2018).

Justifica-se este estudo devido à alta incidência de acidentes no ambiente escolar e a importância do primeiro atendimento adequado em determinadas situações. Visando o planejamento de intervenções educativas para professores que atuam no ambiente escolar, quanto à abordagem das noções básicas de primeiros socorros.

Diante do exposto, constata-se que a temática acidentes no ambiente escolar é de relevância social e de saúde pública, fazendo-se necessária atenção para as situações de urgência e emergência que venham ocorrer com os educandos e para a realização de ações de educação em saúde que contemplem não somente a prevenção, mas também a atuação e a promoção da saúde do escolar.

Sendo assim, esse estudo tem como questão norteadora: qual o conhecimento dos professores que atuam no âmbito escolar acerca dos primeiros socorros? Deste modo, o presente estudo objetivou: identificar os conhecimentos, sobre primeiros socorros de professores que atuam no ambiente escolar frente a situações de urgência e emergência e avaliar o impacto das intervenções educativas sobre primeiros socorros no conhecimento e habilidade dos professores.

\section{Desenvolvimento}

\subsection{Metodologia}

Trata-se de uma revisão integrativa da literatura, que tem como principal objetivo a realização da busca e análise das pesquisas mais relevantes, propiciando um suporte para execução da seleção de estudos, realizandose, assim, uma síntese sobre o conhecimento colhido de um determinado assunto, além de identificar as lacunas que se tem do conhecimento e que necessitam ser preenchidas com o incentivo da realização de novos estudos (MENDES; SILVEIRA; GALVÃO, 2019).

Para o desenvolvimento desta revisão, foram adotadas as seguintes etapas: elaboração da questão norteadora; estabelecimento dos critérios de inclusão e exclusão para a seleção da amostra; análise crítica; interpretação e apresentação dos resultados e conclusões (MENDES; SILVEIRA; GALVÃO, 2019).

A revisão integrativa permite a síntese dos resultados de pesquisas já realizadas, seguindo um processo de análise sistemático e sumarizado da literatura resultando na possibilidade de identificar as possíveis lacunas do conhecimento em relação ao fenômeno em estudo, assim como a necessidade de futuras pesquisas da área em foco (CROSSETTI, 2012).

A pesquisa foi realizada no período de novembro de 2019, nas seguintes bases de dados: Literatura Latino-Americana e do Caribe Ciências da Saúde (LILACS), Banco de Dados em Enfermagem (BDENF) e Medical Literature Analysis and Retrievel System Online (MEDLINE), por meio da Biblioteca Virtual de Saúde (BVS). Para seleção dos artigos, utilizou-se a combinação dos Descritores em Ciências da Saúde (DeCS), em inglês: "Knowledge", "School Teachers" e "First Aid". Durante a pesquisa, foi empregado o uso do operador booleano $A N D$. Optou-se pelo uso dos descritores em língua inglesa por expandir os resultados, quando confrontados ao montante de estudos encontrados utilizando os mesmos descritores em português. Essa estratégia não excluiu estudos publicados em português e espanhol, como se observa nos resultados.

Em seguida, foram realizadas as leituras dos títulos e resumos, adotando como critérios de inclusão: artigos científicos originais, disponíveis na íntegra de forma gratuita, publicados e indexados nos referidos bancos de dados nos últimos 5 anos (2014-2019); em português, inglês e espanhol; que apresentassem relevância com o objeto de estudo e o questionamento norteado. E como critérios de exclusão: artigos que não respondam à questão de pesquisa, relatos de experiência, teses, revisão integrativa, resumos, dissertações 
e publicações duplicadas. Os estudos encontrados em mais de uma base de dados serão considerados somente uma vez.

A partir da utilização da estratégia de busca, foram encontrados 123 estudos científicos, sendo 06 na base de dados BDENF, 18 na LILACS e 101 na MEDLINE. Após a aplicação dos critérios de exclusão e leitura de seus títulos e artigos, foram excluídos 115 estudos, sendo seis por não condizer com os idiomas escolhidos para o estudo, 61 fora do período, oito por apresentarem textos incompletos, uma tese, uma revisão integrativa da literatura, um relato de experiência, um resumo, 16 não disponíveis gratuitamente, 19 não abordaram a temática do estudo e um duplicado.

As informações encontradas que constituíram a amostra do estudo foram examinadas e possibilitou a análise em relação aos seguintes aspectos: identificação do estudo (título do artigo, autores, país, idioma, ano de publicação), características metodológicas do estudo (tecnologia utilizada, público alvo das mesmas, resultados alcançados). A apresentação e discussão dos resultados alcançados foram feitas de forma descritiva, permitindo a avaliação da aplicabilidade da revisão integrativa preparada, de forma a alcançar o objetivo desse método no presente estudo.

\subsection{Resultados}

Na busca eletrônica inicial foram encontrados 123 artigos. Com a análise do idioma e período temporal estipulado, foram selecionados 57 para realização da leitura dos resumos, dos quais foram selecionados oito que seguem os critérios de seleção da amostra que foi previamente estabelecida.

Os artigos eleitos versavam sobre a temática da pesquisa: conhecimento dos professores que atuam no âmbito escolar acerca dos primeiros socorros, nos idiomas inglês $(n=7)$, português $(n=1)$ e espanhol $(n=1)$, publicados entre os anos 2014 e 2019. Destes, identificaram-se publicações originadas no Brasil $(n=2)$, Espanha $(n=1)$, Etiópia $(n=1)$, Irã $(n=1)$, Itália $(n=1)$, Nigéria $(n=1)$ e Sudão $(n=1)$.

Essas publicações tiveram como objetivo a avaliação e identificação do nível de conhecimento ou habilidade de professores escolares (profissionais responsáveis pelo ensinamento em escolas do ensino infantil ao ensino médio), antes e depois de intervenções educativas avaliando-se o impacto desta em diversos temas (Primeiros socorros de maneira geral e direcionado às situações específicasepilepsia). Nos estudos, avaliaram-se amostras que variam entre nove e 317 educadores, sejam isolados ou em paralelo com outros grupos profissionais.

O estudo do material bibliográfico dá-se através da organização do artigo, analisando temas, metodologias e achados nos estudos para serem avaliados na revisão. Sabendo-se disto, os quadros 1 e 2 apresentam a síntese dos estudos incluídos nesta revisão de acordo com seu ano, país de publicação, periódico, título do artigo, autores, objetivo e base de dados; bem como seus principais resultados, método de intervenção e conclusões.

Quadro 1 - Artigos selecionados de acordo com o ano, país de publicação, periódico, títulos do artigo, autores e objetivo

\begin{tabular}{|c|c|c|c|c|c|}
\hline $\mathbf{N}^{\mathbf{0}}$ & Ino/ País & Periódico & Título do Artigo & Autores & Objetivo \\
\hline 01 & $\begin{array}{l}2015 / \\
\text { Nigéria }\end{array}$ & Seizure & $\begin{array}{l}\text { Effect of health education on trainee } \\
\text { teachers' knowledge, attitudes, and } \\
\text { first aid management of epilepsy: An } \\
\text { interventional study. }\end{array}$ & Eze et al. & $\begin{array}{l}\text { Examinar o efeito da educação em saúde no } \\
\text { conhecimento, atitudes e gestão de primeiros } \\
\text { socorros da epilepsia em professores } \\
\text { estagiários na Nigéria. }\end{array}$ \\
\hline 02 & $\begin{array}{l}2015 / \\
\text { Espanha }\end{array}$ & $\begin{array}{c}\text { Enferm. } \\
\text { Universitaria }\end{array}$ & $\begin{array}{l}\text { Educación para la salud en primeros } \\
\text { auxilios dirigida al personal docente } \\
\text { del ámbito escolar. }\end{array}$ & Alba Martin & $\begin{array}{l}\text { Avaliar o aumento do nível de conhecimento } \\
\text { sobre primeiros socorros em professores, } \\
\text { após uma intervenção educacional. }\end{array}$ \\
\hline 03 & $\begin{array}{l}2015 / \\
\text { Itália }\end{array}$ & Ital J & $\begin{array}{l}\text { Teachers of various school grades and } \\
\text { representations of epilepsy: problems, } \\
\text { relational aspects and perspectives of } \\
\text { life quality. }\end{array}$ & $\begin{array}{l}\text { Savarese et } \\
\quad \text { al. }\end{array}$ & $\begin{array}{l}\text { Investigar o nível de conhecimento da } \\
\text { síndrome da epilepsia, as representações de um } \\
\text { grupo de professores sobre a qualidade de vida } \\
\text { das pessoas com epilepsia e as representações } \\
\text { das relações interpessoais entre os alunos com } \\
\text { epilepsia e seus colegas de classe. }\end{array}$ \\
\hline 04 & $\begin{array}{l}2017 / \\
\text { Brasil }\end{array}$ & Rev & $\begin{array}{l}\text { Primeiros socorros na escola: } \\
\text { treinamento de professores e } \\
\text { funcionários. }\end{array}$ & $\begin{array}{l}\text { Calandrin } \\
\quad \text { et al. }\end{array}$ & $\begin{array}{l}\text { Avaliar o conhecimento de professores } \\
\text { e funcionários após um treinamento de } \\
\text { primeiros socorros. }\end{array}$ \\
\hline 05 & $\begin{array}{l}2017 / \\
\text { Sudão }\end{array}$ & Neurc & $\begin{array}{l}\text { Epilepsy: Knowledge, Attitude, and } \\
\text { Practice Among Secondary School } \\
\text { Teachers in Khartoum State. }\end{array}$ & $\begin{array}{c}\text { Elhassan et } \\
\text { al. }\end{array}$ & $\begin{array}{l}\text { Avaliar o conhecimento, a atitude e a prática } \\
\text { de professores do ensino médio em relação à } \\
\text { epilepsia no estado de Cartum, Sudão. }\end{array}$ \\
\hline 06 & $\begin{array}{l}2018 / \\
\text { Brasil }\end{array}$ & $\begin{array}{l}\text { Rev. Bras. } \\
\text { Enferm. }\end{array}$ & $\begin{array}{l}\text { Vivências de professores acerca dos } \\
\text { primeiros socorros na escola. }\end{array}$ & $\begin{array}{l}\text { Galindo Neto } \\
\text { et al. }\end{array}$ & $\begin{array}{l}\text { Desvelar as vivências de professores do } \\
\text { ensino infantil e fundamental sobre primeiros } \\
\text { socorros na escola. }\end{array}$ \\
\hline 07 & $\begin{array}{l}2018 / \\
\text { Etiópia }\end{array}$ & PLoS One & $\begin{array}{l}\text { First aid knowledge, attitude, practice, } \\
\text { and associated factors among } \\
\text { kindergarten teachers of Lideta sub- } \\
\text { city Addis Ababa, Ethiopia. }\end{array}$ & $\begin{array}{l}\text { Gemechu } \\
\text { et al. }\end{array}$ & $\begin{array}{l}\text { Investigar conhecimentos, atitudes, práticas } \\
\text { e fatores associados de primeiros socorros } \\
\text { entre professores do jardim de infância da } \\
\text { sub-cidade de Lideta, Addis Abeba, Etiópia. }\end{array}$ \\
\hline 08 & $\begin{array}{c}2019 / \\
\text { Irã }\end{array}$ & $\begin{array}{l}\text { Rev. Chinesa } \\
\text { Traumatol. }\end{array}$ & $\begin{array}{l}\text { Iranian teachers' knowledge about first } \\
\text { aid in the school environment. }\end{array}$ & $\begin{array}{l}\text { Moh } \\
\text { Kam }\end{array}$ & $\begin{array}{l}\text { Avaliar o conhecimento dos professores } \\
\text { sobre primeiros socorros em Kashan, Irã. }\end{array}$ \\
\hline
\end{tabular}

Fonte: Dados da pesquisa. 
Conforme o gráfico da Figura 1, é possível perceber a quantidade de estudos selecionados dentre as bases de dados utilizadas para a pesquisa a MEDLINE $(n=6,75 \%)$, LILACS $(n=1,17,5 \%)$ e BDENF $(n=1,17,5 \%)$. Valendo-se ressaltar também o ano de publicação destes artigos, onde os estudos predominaram-se no ano de 2015 ( $\mathrm{n}=03,37,5 \%)$, os demais foram realizados em $2017(\mathrm{n}=02,25 \%), 2018(\mathrm{n}=2,25 \%)$ e $2019(\mathrm{n}=1,12,5 \%)$.

Figura 1 - Distribuição dos artigos selecionados de acordo com as bases de dados utilizadas

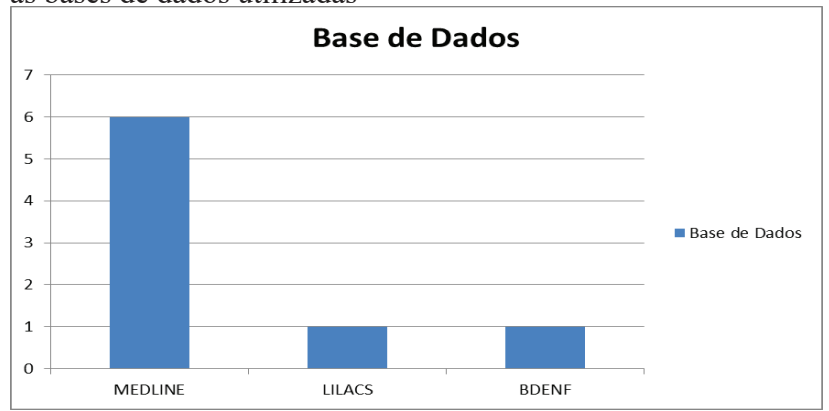

Fonte: Dados da pesquisa.
Não se observa um padrão de métodos de intervenção nos estudos analisados, sendo caracterizados como momentos educativos direcionados aos educadores, palestras, intervenção teórico-prática, coleta de dados, questionários, pré e pós-testes.

Os estudos que englobam testes antes e após a intervenção educativa, foi possível perceber que os pré-testes revelaram resultados inferiores aos pós-testes, que por sua vez apresentaram melhora significativa na média de respostas corretas, quando avaliados conhecimentos e habilidades em PS. Nas conclusões, de todos os artigos, mostrou-se a efetividade das intervenções educativas, melhorando conhecimento dos docentes frente a situações de emergências. Salientando-se também a necessidade da implantação de programas e políticas públicas que levem a educação em saúde em PS para o ambiente escolar, visto sua efetividade constatada.

Quadro 2 - Avaliação e análise das informações específicas dos artigos selecionados. Resumo dos principais resultados, método de intervenção e conclusão demonstrando os principais pontos abordados

\begin{tabular}{|c|c|c|c|c|}
\hline $\mathbf{N}^{\mathrm{o}}$ & Amostra & Principais Resultados & Método de Intervenção & Conclusão \\
\hline 01 & 226 & $\begin{array}{l}\text { A princípio, a maioria }(61,9 \%) \text { e a maior } \\
\text { proporção }(44,2 \%) \text { dos entrevistados tinham } \\
\text { atitudes negativas e pouco conhecimento } \\
\text { sobre epilepsia, respectivamente. } \\
\text { Após a intervenção educativa, aumentou } \\
\text { simultaneamente o conhecimento adequado } \\
29,6 \% \text { e as boas habilidades de gerenciamento } \\
\text { de primeiros socorros aumentaram } 25,0 \% \text { em } \\
\text { relação à linha de base. }\end{array}$ & $\begin{array}{l}\text { Palestra com duração de } 1 \text { h e } 30 \\
\text { min., seguida de uma discussão. }\end{array}$ & $\begin{array}{l}\text { A educação em saúde sobre } \\
\text { epilepsia pode aumentar o } \\
\text { conhecimento e atitudes dos } \\
\text { professores em relação à epilepsia, } \\
\text { facilitando o atendimento correto } \\
\text { dos primeiros socorros. }\end{array}$ \\
\hline 02 & 15 & $\begin{array}{l}\text { Antes da intervenção educativa, a média (em } \\
\text { porcentagem) obtida na } 1^{\text {a }} \text { fase foi de } 38,6 \\
\% \text {, deixando } 8 \text { dos participantes abaixo dessa } \\
\text { média. } \\
\text { A média (em porcentagem) obtida, na } 3^{\text {a fase, }} \\
\text { após a intervenção educacional é de } 76,2 \% \text {, } \\
6 \text { dos participantes permaneceram abaixo da } \\
\text { média. }\end{array}$ & $\begin{array}{l}\text { Intervenção educativa, que } \\
\text { consistiu em } 03 \text { fases interligadas: } \\
1^{\text {a }} \text { fase: pré- questionário (duração } \\
\text { de } 1-2 \mathrm{~h} .) \text {. } \\
2^{\mathrm{a}} \text { fase: intervenção educacional } \\
\text { teórico-prática por uma semana (no } \\
\text { total, } 5 \text { sessões de segunda a sexta- } \\
\text { feira, com duração de } 4 \mathrm{~h} / \text { dia). } \\
3^{\mathrm{a}} \text { fase: pós-questionário (duração } \\
\text { de } 1-2 \mathrm{~h} \text { ). }\end{array}$ & $\begin{array}{l}\text { Houve um aumento notável } \\
(37,6 \%) \text { no conhecimento de } \\
\text { primeiros socorros, o que confirma } \\
\text { o impacto positivo da intervenção. }\end{array}$ \\
\hline 03 & 113 & $\begin{array}{l}\text { Acerca das informações e conhecimentos } \\
\text { sobre epilepsia, os professores com mais de } \\
10 \text { anos de experiência no trabalho ( } 73 \% \text { ) } \\
\text { demonstraram um conhecimento mais do que } \\
\text { adequado sobre transtorno epilético. Ademais, } \\
\text { nos casos em que ocorreram convulsões na } \\
\text { sala de aula, } 45 \% \text { deles ofereceram primeiros } \\
\text { socorros chamando uma ambulância; } \\
\text { medicamentos de resgate foram administrados } \\
\text { por apenas } 9 \% \text { dos professores. }\end{array}$ & $\begin{array}{l}\text { Aplicação de um questionário de } \\
\text { autorrelato. }\end{array}$ & $\begin{array}{l}\text { Existem lacunas significativas } \\
\text { no conhecimento geral dos } \\
\text { professores sobre epilepsia, } \\
\text { seu impacto em contextos } \\
\text { educacionais o gerenciamento } \\
\text { adequado de epilepsia e } \\
\text { convulsões na sala de aula. }\end{array}$ \\
\hline 04 & $35^{*}$ & $\begin{array}{l}\text { Verificou-se antes do treinamento, através da } \\
\text { Avaliação do Conhecimento (teórica) obteve- } \\
\text { se uma média de acertos estatisticamente } \\
\text { significativa de } 37,9 \% \text { e } 91,4 \% \text { depois do } \\
\text { treinamento. }\end{array}$ & $\begin{array}{l}\text { Curso presencial sobre primeiros } \\
\text { socorros ministrado pelos } \\
\text { pesquisadores (duração total } 2 \mathrm{~h} \text { ) e } \\
\text { aplicação de pré e pós-teste. }\end{array}$ & $\begin{array}{l}\text { O treinamento mostrou-se efetivo, } \\
\text { com aumento significativo da } \\
\text { porcentagem de acertos após } \\
\text { o treinamento em primeiros } \\
\text { socorros no ambiente escolar. }\end{array}$ \\
\hline
\end{tabular}




\begin{tabular}{|c|c|c|c|c|}
\hline 05 & 317 & $\begin{array}{l}\text { A maioria dos professores conhecia o termo } \\
\text { "epilepsia" }(93,6 \%) \text { e havia testemunhado uma } \\
\text { crise epiléptica }(83,5 \%) \text {. Mas seu conhecimento } \\
\text { sobre a etiologia, o tratamento e a conduta } \\
\text { diante de situações que exijam a prestação } \\
\text { dos primeiros socorros é geralmente ruim. }\end{array}$ & $\begin{array}{l}\text { Aplicação de um questionário } \\
\text { estruturado. }\end{array}$ & $\begin{array}{l}\text { Existe um nível relativamente } \\
\text { baixo de conhecimento, } \\
\text { principalmente em relação ao } \\
\text { conhecimento sobre tratamento e } \\
\text { a assistência prestada diante dos } \\
\text { primeiros socorros. }\end{array}$ \\
\hline 06 & 9 & $\begin{array}{l}\text { Foram obtidas três categorias, para discussão } \\
\text { da temática: "Conhecimento dos professores } \\
\text { acerca dos primeiros socorros", "Sentimentos } \\
\text { em situações de urgência e emergência" e } \\
\text { "Primeiros socorros vivenciados na escola". }\end{array}$ & Coleta de dados. & $\begin{array}{l}\text { Evidenciaram-se vivências } \\
\text { baseadas em crenças populares, } \\
\text { experiências familiares e lacuna } \\
\text { de conhecimentos acerca da } \\
\text { temática. }\end{array}$ \\
\hline 07 & 194 & $\begin{array}{l}\text { Apenas } 40 \% \text { dos participantes do estudo } \\
\text { possuíam conhecimento prévio sobre } \\
\text { primeiros socorros. A maioria dos } \\
\text { entrevistados mostrou-se disposto em relação } \\
\text { a dar e aprender primeiros socorros. }\end{array}$ & Aplicação de um questionário. & $\begin{array}{l}\text { Baixo conhecimento em primeiros } \\
\text { socorros, tornando-se necessário } \\
\text { considerar a conscientização e a } \\
\text { inclusão de cursos de primeiros } \\
\text { socorros no currículo dos } \\
\text { professores de educação infantil. }\end{array}$ \\
\hline 08 & 200 & $\begin{array}{l}\text { No total, } 40,3 \% \text { dos professores relataram } \\
\text { ter passado por cursos de primeiros socorros } \\
\text { e } 48,5 \% \text { enfrentaram situações em que eram } \\
\text { necessários primeiros socorros no ambiente } \\
\text { escolar. } \\
\text { De modo geral, ninguém possuía bons } \\
\text { conhecimentos de primeiros socorros, mas } \\
63,3 \% \text { e } 36,7 \% \text { apresentaram conhecimento } \\
\text { moderado ou fraco de primeiros socorros, } \\
\text { respectivamente. }\end{array}$ & Aplicação de questionário. & $\begin{array}{l}\text { A maioria dos professores possuía } \\
\text { conhecimento } r \text { insuficiente } \\
\text { em primeiros socorros, não } \\
\text { participaram de nenhum } \\
\text { treinamento em primeiros } \\
\text { socorros. Ações urgentes parecem } \\
\text { necessárias para a formação } \\
\text { de professores em primeiros } \\
\text { socorros por meio de programas } \\
\text { de treinamento em serviço. }\end{array}$ \\
\hline
\end{tabular}

$\mathrm{O}$ estudo que recebeu um asterisco inclui em sua amostra professores $(\mathrm{n}=29)$ e outros profissionais que atuam na escola $(n=6)$, não sendo possível a diferenciação entre as categorias dos outros profissionais, nem dos resultados por cada classe profissional (CALANDRIN et al., 2017).

\subsection{Discussão}

Segundo Mohsen e Kamrava (2019), 48,5\% dos educadores enfrentaram situações em que era necessário prestar assistência de primeiros socorros no ambiente escolar, os incidentes mais comuns que acometeram os escolares foram respectivamente desmaio e convulsão (15,8\%), feridas $(14,7 \%)$ e picada de inseto $(12,6 \%)$. Diante de tais situações, $85,7 \%$ dos professores sabiam o número de telefone que deve ser chamado em casos de emergência no Irã.

Algumas condutas de PS são conhecidas pelos professores através de vivências baseadas em crenças populares, os profissionais apresentam alguns conhecimentos construídos do senso comum. Sejam eles adquiridos através de suas experiências maternas, por envolver o cuidado com os filhos que adoecem e se acidentam na infância levando as mães a buscarem informações acerca da forma correta de socorrer, ou interações com o meio por intermédio da crença alicerçada em mitos populares e experiências familiares (CALANDRIN et al., 2017; GALINDO NETO et al., 2018).

Os professores relatam não haver recebido treinamentos prévios sobre PS e que obtiveram seu próprio conhecimento através das seguintes fontes de informação: mídia (televisão, rádio, jornal, revistas), livros, internet (ALBA MARTIN, 2015; EZE et al., 2015; GEMECHU et al., 2018; MOHSEN; KAMRAVA, 2019). Contestando o que diz Calandrin et al. (2017), onde 42,8\% dos participantes de seu estudo relataram já haver recebido treinamento prévio sobre PS por profissionais da saúde.

Apontam-se um conhecimento inadequado de docentes escolares diante de situações gerais e específicas (epilepsia) que exijam noções de PS (SAVARESE et al., 2015). Em estudo realizado no Brasil, identificou-se que existe entre os professores a consciência de que estão despreparados para prestar os PS, principalmente diante da complexidade que envolve uma situação de urgência e emergência (GALINDO NETO et al., 2018).

Ao avaliar o conhecimento dos educadores de escolas públicas e privadas do ensino fundamental e médio no Irã, verificou-se que a maioria dos participantes apresenta conhecimento inadequado sobre PS, dessa forma diminuindo a chance dos alunos receberem assistência de PS adequados e oportunos, tendo como consequência o aumento das complicações após os incidentes no âmbito escolar (MOHSEN; KAMRAVA, 2019).

Diante do pouco conhecimento de professores que atuam no âmbito escolar acerca dos PS, em estudo realizado no México, evidenciou-se implementar um programa educacional de PS, destinado a professores abrangendo o ensino infantil, fundamental e médio, para melhoria do conhecimento e habilidades (ALBA MARTIN, 2015). Mais 
de $95 \%$ dos professores demonstraram interesse em aprender PS. Esses achados mostram que os professores estão cientes da importância de ter um conhecimento adequado das noções básicas em PS (MOHSEN; KAMRAVA, 2019).

Nesse contexto, os estudos analisados nessa revisão contribuem para a análise dos conhecimentos sobre PS e a compreensão de que o impacto de intervenções educativas, apontam para a necessidade do planejamento e implementação de ações contínuas e a realização de novos estudos acerca da temática.

Em estudo realizado numa escola no interior de São Paulo, o método de intervenção utilizado apresentou resultados positivos, quando confrontados aos resultados anteriores à intervenção educativa, conforme observado à melhora de $91,4 \%$ dos sujeitos frente à média de acertos estatisticamente, apontando melhora significativa após o curso presencial de PS com duração de duas horas. A pontuação média antes do treinamento foi de 19,43 pontos (máximo 180 pontos) referente às habilidades e uma média de 2,91 pontos (máxima 10 pontos) referentes ao conhecimento. Após o treinamento as médias obtidas referentes às habilidades e ao conhecimento foram 174,57 e 9,15, respectivamente (CALANDRIN et al., 2017).

Segundo Eze et al. (2015), em um estudo realizado no Colégio Federal de Educação no estado de Lagos, sudoeste da Nigéria, através de intervenção educacional compreendendo uma palestra com duração de uma hora e 30 minutos, abordando os PS em epilepsia, houve um aumento significativo acerca do conhecimento $(29,6 \%)$, atitudes positivas $(16,4 \%)$ e boas habilidades nas noções de primeiros socorros $(25,0 \%)$ prestadas à estudantes com epilepsia doze semanas após a intervenção.

É de suma importância que o Ministério da Educação (MEC) em conjunto com as autoridades e formuladores das políticas públicas, implementem por meio de programas de ensino o treinamento em PS para todos os professores escolares, dessa melhoraria a segurança de todos no ambiente escolar, sendo realizado a cada ano ou dois anos a reciclagem desses profissionais para mantê-los atualizados sobre as novas diretrizes. Visando tornar este tipo de capacitação obrigatória para professores e estudantes universitários, que se tornarão futuros educadores escolares (ALBA MARTIN, 2015; ELHASSAN et al., 2017; EZE. et al., 2015; MOHSEN; KAMRAVA, 2019).

A amostra de professores dos estudos incluídos nessa revisão variou entre 9 e 317 docentes. A avaliação das habilidades e conhecimentos ocorreu em grupos isolados de professores ou em comparação a outros grupos profissionais.

Nesse contexto impossibilitou-se afirmar qual das metodologias adotadas nas intervenções educativas e aplicadas nos estudos selecionados tornou-se mais eficaz no aprimoramento de conhecimento ou habilidade. Fazendose necessárias pesquisas posteriores comparando diferentes metodologias.

\section{Conclusão}

Acidentes no âmbito escolar são frequentes e podem ocorrer a qualquer momento, caso não haja intervenção de primeiros socorros precoce diante desses incidentes pode-se provocar sequelas irreversíveis. Dessa forma, é importante o treinamento dos professores escolares quanto às práticas de PS, assim como, o reconhecimento de ações voltadas para prevenção e promoção dos agravos na saúde do escolar, objetivando melhor qualidade de vida das crianças, visto que se tornam responsáveis pelos alunos no período em que se encontram na escola.

Os estudos reforçam a precariedade dos conhecimentos e habilidades em primeiros socorros pelos educadores escolares, onde o assunto ainda é pouco difundido no âmbito escolar, sendo restrito na maioria das vezes aos profissionais de saúde. Podendo levar a atitudes inadequadas nos atendimentos às vítimas de acidente, tendo como consequências sequelas e até mesmo a morte.

Faz-se necessário, o trabalho integrado do Ministério da Saúde, com o apoio de parlamentares, e do Ministério da Educação, com o intuito de formular políticas públicas mais rígidas abrangendo essa temática. Pois, mesmo com a Lei Lucas em vigor desde outubro de 2018, as instituições de ensino ainda descumprem as regras impostas, negligenciando $\mathrm{o}$ atendimento de PS prestados às vítimas de acidentes nas escolas.

Desta forma, pretende-se com esse estudo estimular o desenvolvimento pesquisas futuras que explorem amplamente a temática, provendo embasamento científico e ferramentas para essas práticas, melhorando a sua eficácia, e incentivando profissionais a dedicarem-se a essa atividade. Sugeremse novos estudos que investiguem claramente a efetividade de diferentes abordagens, visto que se tornou impossível concluir qual metodologia foi mais efetiva na melhoria de conhecimentos e habilidades dos professores.

\section{Referências}

ALBA MARTIN, R. Educación para la salud en primeros auxilios dirigida al personal docente del ámbito escolar. Enferm. Univers., v.12, n.2, p.88-92, 2015. doi: https://doi.org/10.1016/j. reu.2015.04.004

BRASIL. Lei Federal $N^{\circ} 13.722$, de 04 de outubro de 2018. Torna obrigatória a capacitação em noções básicas de primeiros socorros de professores e funcionários de estabelecimentos de ensino públicos e privados de educação básica e de estabelecimentos de recreação infantil. Disponível em: http://www.planalto.gov.br/ ccivil 03/ ato2015-2018/2018/lei/L13722.htm. Acesso em: 26 out. $2 \overline{0} 20$.

CABRAL, E.V.; OLIVEIRA M.F.A. Primeiros Socorros na escola: conhecimento dos professores. Ens., Emb. Saúde. 2017. doi: https://doi.org/10.22409/resa2017.v10i1.a21255

CALANDRIN, L.F. et al. Primeiros socorros na escola: treinamento de professores e funcionários. Rev. Rene, 2017. doi: https://creativecommons.org/licenses/by/4.0/.

CARMO, H.O. et al. Atitudes dos docentes de Educação Infantil em situação de acidente escolar. Rev. Enferm. Centro-Oeste 
Mineiro, 2017. doi: https://doi.org/10.19175/recom.v7i0.1457

CONTI, K.L.M.; ZANATTA, S.C.Z. Acidentes no ambiente escolar: uma discussão necessária. Cadernos PDE. 2014. Disponível em: http:/www.diaadiaeducacao.pr.gov.br/portals/ cadernospde/pdebusca/producoes_pde/2014/2014_unesparparanavai_cien_artigo_kesia_liriam_meneguel.pdf. Acesso em: 26 out. 2020 .

CROSSETTI M, G.O. Revisão integrativa de pesquisa na enfermagem o rigor científico que lhe é exigido. Rev. Gaúcha Enferm., v.23, n.2, p.8-9. 2012.

ELHASSAN, M. A. et al. Epilepsy: Knowledge, Attitude, and Practice Among Secondary School Teachers in Khartoum State. Neurol. Ther, v.6, n.2, p.225-235, 2017. doi: 10.1007/s40120017-0083-7.

EZE, C.N. et al. Effect of health education on trainee teachers' knowledge, attitudes, and first aid management of epilepsy: an interventional study. Seizure, v.33, p.46-53, 2015. doi: 10.1016/j. seizure.2015.10.014.

GALINDO NETO, N.M. et al. Vivências de professores acerca dos primeiros socorros na escola. Rev. Bras. Enferm., 2018. doi: https://doi.org/10.1590/0034-7167-2017-0715

GEMECHU, G. et al. First aid knowledge, attitude, practice, and associated factors among kindergarten teachers of Lideta subcity Addis Ababa, Ethiopia. PLoS One, 2018. 10.1371/journal. pone. 0194263
LEITE, A.C.Q.B. et al. Primeiros socorros nas escolas. Rev. Extendere, 2013. Disponível em: http://periodicos.uern.br/index. php/extendere/article/viewFile/778/429. Acesso em: 26 out. 2019.

MEIRELES, G.O.A.B. A abordagem de primeiros socorros realizada pelos professores em uma unidade de ensino estadual em Anápolis - GO. Ensaios Ciênc. Ciênc. Biol., Agrárias Saúde. 2014. doi: 10.17921/1415-6938.2014V18N1P\%P

MENDES, K.D.S.; SILVEIRA, R.C.C.P.; GALVÃO, C.M. Uso de gerenciamento de referências bibliográficas na seleção dos estudos primários em revisão integrativa. Texto Contexto Enferm, v.28, p.758-764, 2019. doi: http://dx.doi.org/10.1590/1980-265xtce-2017-0204

MOHSEN, A. H.; KAMRAVA, Z. Iranian teachers' knowledge about first aid in the school environment. Rev. Chinesa Traumatol., 2019. doi: https://doi.org/10.1016/j.cjtee.2019.02.003

SAVARESE, G. et al. Teachers of various school grades and representations of epilepsy: problems, relational aspects and perspectives of life quality. Ital. J. Pediatr., 2015. doi: 10.1186/ s13052-015-0177-8

SLABE, D. et al. Knowledge of health principles among professionals in Slovenian kindergartens. Zdr Varst. 2016. doi: 10.1515/sjph-2016-0024.

SÖNMEZ, Y. et al. Knowledge levels of pre-school teachers related with basic firstaid practices, isparta sample. Turk Pediatri Ars, v.49, n.3, p.238-246, 2014. doi: 10.5152/tpa.2014.1581 